\title{
POSTSCRIPTUM POLONISTYCZNE
}





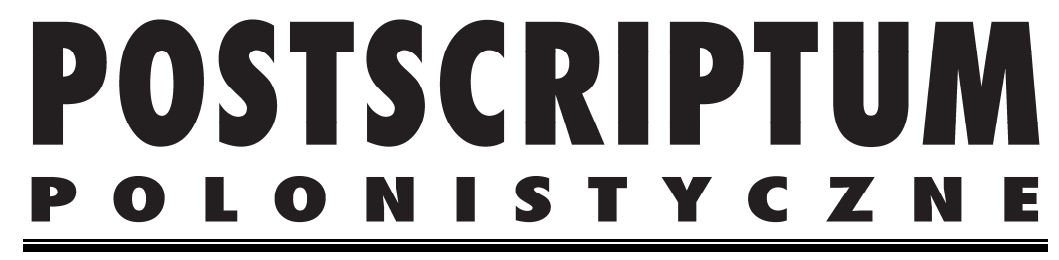

\title{
$2018 \cdot 1(21)$
}

\author{
Redakcja \\ ROMUALD CUDAK - redaktor naczelny \\ JOLANTA TAMBOR - zastępca redaktora naczelnego \\ ALEKSANDRA ACHTELIK, MAGDALENA BĄK, \\ MARCIN MACIOLEK, AGNIESZKA MADEJA, AGNIESZKA NECKA, \\ BERNADETA NIESPOREK-SZAMBURSKA, KAROLINA POSPISZIL \\ MARIA CZEMPKA-WEWIÓRA - sekretarz redakcji
}

\section{Rada Programowa}

KALINA BACHNEWA Sofia, JERZY BARTMIŃSKI Lublin, ANNA DĄBROWSKA Wrocław, MARIA DELAPERRIÈRE Paryż, KATARZYNA DZIWIREK Seattle, ELWIRA GROSSMAN Glasgow, KRIS VAN HEUCKELOM Leuven, MALGORZATA KITA Katowice, AŁŁA KOŻYNOWA Mińsk, LUIGI MARINELLI Rzym, MICHAŁ MASEOWSKI Paryż, GERHARD MEISER Halle, WŁADYSEAW T. MIODUNKA Kraków, LÁSZLÓ K. NAGY Debreczyn, ALEKSANDER NAWARECKI Katowice, WACŁAW M. OSADNIK Edmonton, KAZIMIERZ OŻÓG Rzeszów, ANNA MAŁGORZATA PACKALÉN PARKMAN Uppsala, TOKIMASA SEKIGUCHI Tokio, MARIE SOBOTKOVÁ Ołomuniec,

TAMARA TROJANOWSKA Toronto, MARIA WOJTAK Lublin 


\title{
POSTSCRIPTUM \\ P O L N ISTYCZNE
}

Pismo jest kontynuacją półrocznika „Postscriptum”, który ukazywał się od 1992 do 2007 r.

Wersja elektroniczna: www.postscriptum.us.edu.pl

Pismo recenzowane naukowo.

Nazwiska recenzentów podawane są łącznie raz w roku na stronie internetowej:

www.postscriptum.us.edu.pl.

Wersja papierowa jest wersja pierwotną (referencyjna) pisma.

C Copyright by Uniwersytet Śląski w Katowicach

\author{
Redaktorki numeru \\ MAGDALENA BAূK \\ AGNIESZKA MADEJA \\ Redakcja językowa \\ MAGDALENA BĄK \\ AGNIESZKA MADEJA \\ Projekt okładki, layout i łamanie \\ MAREK FRANCIK
}

Publikacja sfinansowana ze środków

UNIWERSYTETU ŚLASSIEGO W KATOWICACH

Adres redakcji

„Postscriptum Polonistyczne”

Szkoła Języka i Kultury Polskiej UŚ

Katedra Międzynarodowych Studiów Polskich UŚ

pl. Sejmu Śląskiego 1, 40-032 Katowice

tel./faks: +48 322512991, tel. 48322009424

e-mail: postscriptum@us.edu.pl

www.postscriptum.us.edu.pl

Wydawca

Wydawnictwo Uniwersytetu Śląskiego

ul. Bankowa 12B, 40-007 Katowice

www.wydawnictwo.us.edu.pl

e-mail:wydawus@us.edu.pl

Nakład: $120+35$, cena 16 zł (+VAT)

ISSN 1898-1593 


\section{Spis treści}

\section{Rozprawy}

Szkice polsko-portugalskie

BEATA CIESZYŃSKA: Sarmatyzm i sebastianizm w perspektywie iberyjsko-słowiańskiej. Wokół lizbońskiego projektu „Vieira Global” ....13 EWA LUKASZYK: Raczyński w Portugalii.

Spuścizna „zderzenia kultur”

MAGDALENA BAূK: Apetyt na Bragę. O intertekstualnym dialogu

między Adolfem Pawińskim a Oswaldem Crawfurdem

i o dziewiętnastowiecznym podróżowaniu

LIDIA ROMANISZYN-ZIOMEK: Capa e batina,

czyli o tradycjach akademickich Portugalii

TERESA FERNANDES SWIATKIEWICZ: Normy wstępne

w bezpośrednim przekładzie literatury polskiej

na europejski portugalski w latach 1985-2010

MARCIN ZIOMEK: Lizbona - stolica europejskiego street artu(?)

Szkice polsko-brazylijskie

MARCElo PaIVA DE SOUZA: Kamień i horyzont: spojrzenie na Siciliane

Murila Mendesa w kontekście twórczości Zbigniewa Herberta

PIOTR KILANOWSKI: O tym, co można ujrzeć po drugiej stronie lustra,

czyli garść refleksji o odbiciach, tłumaczeniach i wierszach

GABRIEL BOROWSKI: O obecności poezji brazylijskiej w Polsce:

Carlos Drummond de Andrade

ANNA WOLNY: Na marginesie historii i literatury -

kilka uwag o brazylijskiej figurze polaca

ALEKSANDRA PluTA: Mrożek i jego Tango w Brazylii 161

ALICJA GOCZYŁa FERREIRA: Polskość na antypodach: wybrane aspekty

historyczne i językowe polskiej obecności w Brazylii

MARCIN RAIMAN: O moźliwości kooficjalizacji języka polskiego na terenie brazylijskich municypiów 
WŁADYSŁAW T. MiODUNKA: Bilingwizm polsko-portugalski w Brazylii.

Od znajomości polszczyzny do tłumaczenia literatury polskiej

na portugalski

JOLANTA TAMBOR: Po polsku, po brazylijsku i po portugalsku

- o świadomości językowej Polonii brazylijskiej.

Odrodzenie i zanikanie języka 221

ALEKSANDRA PIASECKA-TILL: Uczymy języka polskiego w Kurytybie: uniwersytecki projekt Licenciar

\section{Wywiady}

Opcja na rzecz zbliżenia. Z Henrykiem Siewierskim rozmawia João Vianney Cavalcanti Nuto 255

Warsztaty metodyczne w Kurytybie. Rozmowa z Paulem Kochannym, ekspertem ds. polonijnych w Konsulacie RP w Kurytybie

\section{Recenzje}

ANNA JAMroZEK-SOWA: Taki Paryż w tropikach.

Recenzja książki Aleksandry Pluty:

Droga do Rio. Historie polskich emigrantów

MALgORZATA WIĘZIK: Album z podróży po Portugalii.

Recenzja książki Magdaleny Bąk, Lidii Romaniszyn-Ziomek:

„Gdzie ziemia sie kończy, a morže zaczyna”. Szkice polsko-portugalskie

Agnieszka Madeja: Pan Cogito w Brazylii.

Recenzja zbioru wierszy Zbigniewa Herberta:

Podróż Pana Cogito. A viagem do Senhor Cogito

Przeglądy 295

AgNIESZKA NĘCKA: Półka literacka 2017 297

AGNIESZKA TAMBOR: Półka filmowa sezonu 2017 313

Noty o autorach 325 


\section{Contents}

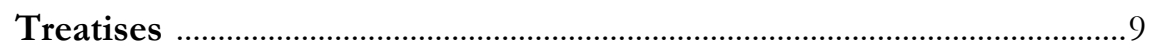

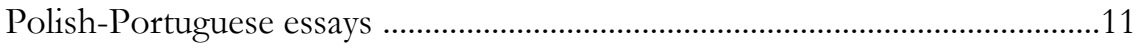

BEATA CIESZYŃSKA: Sarmatism and Sebastianism in Ibero-Slavonic perspective. A 'Vieira Global' project in Lisbon ................13 EWA LuKASZYK: Raczyński in Portugal.

Heritage of the 'clash of cultures'

MAGDALENA BAK: Appetite for Braga.

On intertextual dialog between Adolf Pawiński and Oswald Crawfurd and the 19th century travelling

LIDIA ROMANISZYN-ZIOMEK: Capa e batina.

On academic traditions in Portugal

TERESA FERNANDES SWIATKIEWICZ: Preliminary norms in direct Polish-European Portuguese literary translation in the period between 1985 and 2010

MARCIN ZIOMEK: Lisbon - a capital of European street art(?)

Polish-Brazilian essays

MARCELO PAIVA DE SOUZA: A stone and a horizon:

Siciliana by Murilo Mendes regarded through

Zbigniew Herbert's writing

PIOTR KILANOWSKI: What can be found on the other side of the mirror. On reflections, translations and poems

GABRIEL BOROWSKI: On the presence of Brazilian poetry in Poland: the case of Carlos Drummond de Andrade

ANNA WOLNY: Margins of history and literature -

a few remarks on Brazilian figure of polaca

ALEKSANDRA PLUTA: Mrożek and his Tango in Brazil

Alicja GOCZYŁa FERrEIRA: Poles on the antipodes.

Selected historical and language aspects of Polish presence in Brazil .... 173 
MARCIN RAIMAN: On the possibility of introducing Polish language as a co-official one in the area of Brazilian municipalities 187

WŁAdystaW T. MIODUNKA: Polish-Portuguese bilingualism in

Brazil. Speaking Polish and translating Polish literature

JOLANTA TAMBOR: Speaking Polish, Brazilian and Portuguese -

on language awareness of Polish diaspora in Brazil. Revival

and disappearance of a language

ALEKSANDRA PIASECKA-TILL: We teach Polish in Curitiba:

university project Licenciar

Interviews

Bring closer together. Henryk Siewierski interviewed

by João Vianney Cavalcanti Nuto

Workshops for teachers in Curitiba. Interview with Paulo Kochanny

(Consulate of the Republic of Poland in Curitiba)

Reviews

ANNA JAMROZEK-SOWA: Review of Aleksandra Pluta's book:

Droga do Rio. Historie polskich emigrantów

MALGORZATA WIEZZIK: Travel sketches from Portugal.

Review of the book by Magdalena Bąk and Lidia Romaniszyn-Ziomek:

„Gdzie ziemia sie kończy, a morze zacsyna”. Szkice polsko-portugalskie

AgNiesZKa Madeja: Mr. Cogito in Brazil.

Review of Zbigniew Herbert's poetry book:

Podróż Pana Cogito. A viagem do Senhor Cogito

Przeglądy 295

AgNIESZKA NĘCKA: Literary shelf 2017 297

AGNIESZKA TAMBOR: Film shelf 2017 


\section{Noty o autorach}

Magdalena Bąk - dr hab., Instytut Nauk o Literaturze Polskiej im. Ireneusza Opackiego, Uniwersytet Śląski w Katowicach, Polska.

Adiunkt w Zakładzie Historii Literatury Oświecenia i Romantyzmu Uniwersytetu Śląskiego. Jej zainteresowania badawcze skupiają się wokół problemów związanych z literaturą romantyzmu. Bada także wątki australijskie i portugalskie w literaturze polskiej (szczególnie dziewiętnastowiecznej). Jest autorką publikacji: Mickiewicz jako erudyta (w okresie wileńsko-kowieńskim i rosyjskim) (2004), Pan Australski i złoto Wiktorii. Wspomnienia Seweryna Korzelinskiego (2011), Twórçyy lek Stowackiego. Antagonizm wiesz̧czón po latach (2013), Gdzie diabet (tasmański) mówi dobranoc. Wizerunek. Australii w literaturze polskiej (2014), „Gdzie ziemia sie kończy, a morze zaczyna”. Szkice polsko-portugalskie (2016, wspólnie z L. Romaniszyn-Ziomek).

Kontakt: magdalena.bak@us.edu.pl

Gabriel Borowski - dr, Zakład Filologii Portugalskiej i Przekładoznawstwa, Uniwersytet Jagielloński, Kraków, Polska.

Brazylianista i przekładoznawca, tłumacz, członek m.in. American Comparative Literature Association oraz Centro de Literaturas e Culturas Lusófonas e Europeias da Faculdade de Letras da Universidade de Lisboa, laureat pierwszej edycji programu „Diamentowy Grant”, autor publikacji poświęconych literaturom portugalskiego obszaru językowego oraz przekładowi literatury, współredaktor tomów Punkt widzenia w literaturze, kulturze i jezyku (2015) oraz Diálogos no feminino: Maria Pawlikowska-Jasnorzewska \& Florbela Espanca (2017).

Kontakt: gabriel.borowski@uj.edu.pl

Beata Cieszyńska - dr, Centro de Literaturas e Culturas Lusófonas e Europeias da Faculdade de Letras da Universidade de Lisboa, Portugalia.

Literaturoznawca, historyk literatury, komparatysta. Jej zainteresowania badawcze to mity i stereotypy w czytaniu Obcego w perspektywie polsko-brytyjskiej oraz iberyjsko-słowiańskiej. Koordynator Grupy Naukowej CLEPUL 5 badającej kontakty i porównania iberyjsko-słowiańskie (Inter- 
culturalidad Ibero-eslava). Autorka książki Okna duszy. Pię́ zmystów w literaturze barokowej (2006). Redaktorka zbioru Iberian and Slavonic Cultures: Contact and Comparison (2007), rocznika „IberoSlavica”; współredaktorka półrocznika „Letras Com Vida” oraz ksiazzek: Peripheral Identities. Iberia and Eastern Europe between the Dictatorial Past and the European Present (2011); Estudos de género na perspectiva ibero-eslava (2014, wspólnie z F.M. Silva); A Missão e o Messianismo na perspectiva ibérica e eslava (2016, wspólnie z F.M. Silva).

Kontakt: b_ciesz@poczta.onet.pl

Teresa Fernandes Swiatkiewicz - dr, Centro de Literaturas e Culturas Lusófonas e Europeias da Faculdade de Letras da Universidade de Lisboa, Portugalia.

Z zawodu nauczyciel i lektor języka angielskiego i portugalskiego. Z zamiłowania tłumacz literatury polskiej na język portugalski (tlumaczyła dzieła: Antoniego Libery, Pawła Huellego, Jana T. Grossa, Leopolda Kielanowskiego, Wisławy Szymborskiej, Czesława Miłosza, Tadeusza Różewicza, Zbigniewa Herberta, Michała Rusinka, Andrzeja Wajdy, Kazimierza Kutza, Krzysztofa Kieślowskiego, Ireny Kamieńskiej, Marcela Lozińskiego). Publikuje artykuły o literaturze polskiej. Odznaczona przez Prezydenta RP Złotym Krzyżem Zasługi w 2012 roku.

Kontakt: tswiatkiewicz@gmail.com

Alicja Goczyła Ferreira - mgr, Departamento de Polonês, Alemão e Letras Clássicas, Universidade Federal do Paraná, Kurytyba, Brazylia.

Wykładowczyni języka i literatury polskiej. W latach 2006-2014 była nauczycielką języka polskiego w Centrum Języków i Interkulturowości przy Universidade Federal do Paraná. Do kręgu jej zainteresowań naukowych należy obecność języka polskiego w Brazylii, jego historia i współczesność w kontekście kontaktu językowego. Jest autorką rozdziałów o Irenie Sendlerowej oraz Antoninie i Janie Żabińskich w zbiorze Memórias de Luæ: Histórias de Poloneses Justos pod red. Piotra Kilanowskiego.

Kontakt: alicja.ferreira@ufpr.br

Anna Jamrozek-Sowa - dr, Instytut Filologii Polskiej, Uniwersytet Rzeszowski, Polska.

W pracy naukowej skupia się na badaniu narracji migracyjnych XIX-XXI wieku, literatury postzależnościowej, literatury środkowoeuropejskiej i państw bałkańskich, pism literackich jako środowisk kulturotwórczych, dziedzictwa awangardowego teatru polskiego. Jest autorką monografii naukowych poświęconych pisarstwu Zofii Romanowiczowej oraz Władysława Lecha Terleckiego, redaktorką m.in. książek o tematyce teatrologicznej. Należy 
do zespołu redakcyjnego pisma literacko-artystycznego „Fraza” oraz Rocznika Wydziału Sztuki UR „Warstwy”.

Kontakt: a_js@op.pl

Piotr Kilanowski - dr, Departamento de Polonês, Alemão e Letras Clássicas, Universidade Federal do Paraná, Kurytyba, Brazylia.

Interesuje się literaturą XX wieku, poezją (głównie polską) i jej przekładem. Opublikował m.in. książkowe wydania tłumaczeń wierszy Zbigniewa Herberta, Anny Świrszczyńskiej (na portugalski) i Paula Leminskiego (na polski).Wśród pozycji złożonych do publikacji w 2018 roku znajdują się m.in. tomiki Wisławy Szymborskiej, Jerzego Ficowskiego i Władysława Szlengla. Wśród tłumaczeń drukowanych w czasopismach są m.in. przekłady Aleksandra Wata, Czesława Miłosza, Wisławy Szymborskiej, Josifa Brodskiego i Stanisława Lema. Zredagował i opracował książki Memórias de luz. (2015) i Leituras e reflexões (1998). Autor ok. 30 artykułów i rozdziałów prac naukowych poświęconych literaturze.

Kontakt: emaildopiotr@gmail.com

Paulo Cesar Kochanny - ekspert ds. polonijnych, Konsulat Generalny RP w Kurytybie, Brazylia.

Interesuje się Polonią w Kurytybie, folklorem, historią polskiej emigracji do Brazylii.

Kontakt: paulo.kochanny@msz.gov.pl

Ewa Lukaszyk - dr hab., LE STUDIUM Loire Valley Institute for Advanced Studies, Orléans, Francja.

Literaturoznawca o orientacji komparatystycznej i krytyk kultury, specjalista w zakresie studiów śródziemnomorskich i luzytanistycznych. Dwukrotna stypendystka Fundacji Calouste'a Gulbenkiana w Lizbonie i autorka licznych publikacji poświęconych Portugalii, m.in. książki Imperium i nostalgia. „Styl późny” w kulturze portugalskiej (2015). Prowadziła też badania nad wieloma kulturami pozaeuropejskimi, m.in. w Malezji, Maroku, Gwinei-Bissau. Obecnie pracuje nad koncepcją humanistyki transkulturowej i realizuje projekt badawczy „Poszukiwanie języka adamowego i wyłonienie się aspiracji transkulturowej w następstwie europejskich odkryć morskich", finansowany ze środków Horizon 2020.

Kontakt: ewaluk@al.uw.edu.pl

Agnieszka Madeja - dr, Szkoła Języka i Kultury Polskiej, Uniwersytet Śląski w Katowicach, Polska.

Jej zainteresowania dotyczą zagadnień glottodydaktycznych oraz językoznawczych, w szczególności z zakresu leksykografii historycznej i rozwoju 
zasobu leksykalnego polszczyzny. Od 1998 roku zajmuje się nauczaniem języka polskiego jako obcego na różnych poziomach zaawansowania. Jest współautorką podręczników i pomocy dydaktycznych dla cudzoziemców. Członkini ministerialnych komisji rekrutacyjnych osób pochodzenia polskiego na studia w Polsce oraz egzaminatorka i wizytatorka Państwowej Komisji do spraw Poświadczania Znajomości Języka Polskiego jako Obcego.

Kontakt: agnieszka.madeja@us.edu.pl

Władysław T. Miodunka - prof. zw. dr hab., Katedra Języka Polskiego jako Obcego, Uniwersytet Jagielloński, Kraków, Polska.

Profesor emerytowany. Językoznawca specjalizujący się w badaniach języka polskiego w świecie, bilingwizmu polsko-obcego i w badaniach z zakresu glottodydaktyki polonistycznej. Od 1973 roku zajmuje się nauczaniem polszczyzny jako języka obcego i drugiego w Polsce i świecie. Jest autorem wielu prac naukowych z tego zakresu oraz redaktorem serii podręczników i rozpraw naukowych z obszaru glottodydaktyki polonistycznej. W latach 2003-2016 kierował pracami Państwowej Komisji Poświadczania Znajomości Języka Polskiego jako Obcego. Jest członkiem Rady Języka Polskiego i twórcą krakowskiej szkoły glottodydaktyki porównawczej.

Kontakt:w.miodunka@uj.edu.pl

Agnieszka Nęcka - dr hab., Instytut Nauk o Literaturze Polskiej im. Ireneusza Opackiego, Uniwersytet Śląski w Katowicach, Polska.

Krytyk literacki współpracujący m.in. z „artPAPIEREM”, „Nowymi Książkami”, „Pograniczami”, „Twórczością”; autorka książek: Granice prayzwoitości. Doświadcæenie intymności w prozie najnowszej (2006), Starsze, nowsze, najnowsze. Szkice o prozie polskiej XX i XXI wieku (2010), Cielesne o(d)stony. Dyskursy erotyczne w polskiej prozie po 1989 roku (2011), Co ważne i ważniejsze. Notatki o prozie polskiej XXI wieku (2012), Emigracje intymne. O wspótczesnych polskich narracjach autobiograficznych (2013), Polifonia. Literatura polska poczatku XXI wieku (2015). Redaktor działu krytyki literackiej w „Postscriptum Polonistycznym”. Stypendystka Marszałka Województwa Śląskiego w dziedzinie kultury (2009).

Kontakt: agnieszka.necka@us.edu.pl

Marcelo Paiva de Souza - dr, Departamento de Polonês, Alemão e Letras Clássicas, Universidade Federal do Paraná, Kurytyba, Brazylia.

Literaturoznawca, przekładoznawca, tłumacz. Opublikował m.in. książkę Teatr niepokoju: studium porównawcze dramaturgii Stanisława Ignacego Witkiewicza $i$ Oswalda de Andrade (2001). Współredagował tom zbiorowy Sob o signo de 
Babel: literatura e poéticas da tradução (2006). Przetłumaczył m.in. Fortepian Szopena Cypriana Norwida (1994, wspólnie z H. Siewierskim), Podróż Idy Fink (1998), Iwone, ksieżniçke Burgunda Witolda Gombrowicza (2003), Wojne polsko-ruska pod flagq biato-czerwona Doroty Masłowskiej (2007) i Świadectwo poezji Czesława Miłosza (2012).

Kontakt:mrclpvdsz@hotmail.com

Aleksandra Piasecka-Till - dr, Departamento de Polonês, Alemão e Letras Clássicas, Universidade Federal do Paraná, Kurytyba, Brazylia.

Prowadzi badania dyskursu mediów, kwestii genderowych i tych związanych z tożsamością i internacjonalizacją szkolnictwa. Kształci nauczycieli języków angielskiego i polskiego, rozwijając ich kompetencje międzykulturowe. Zajmuje się teorią i praktyką tłumaczenia. Autorka Buscando o Significado em um Corpus: PC, Sexismo e suas Inflexões no Banco de Lingua Inglesa do Cobuild (2006) i Using Metaphors to Disparage Political Correctness: a critical discourse analysis of lexical choices in British newspapers (2005).

Kontakt: piasecka@yahoo.com

Aleksandra Pluta - mgr, Instituto de Letras, Universidade de Brasília, Brazylia.

Stypendystka CAPES. Magister dziennikarstwa na Università La Sapienza w Rzymie. Autorka książek na temat polskiej imigracji w krajach Ameryki Łacińskiej, m.in. Na fali historii. W spomnienia Polaków w Chile (2009), Ten piekielny polski akcent. Ziembinski na brasylijskiej scenie (2015), Droga do Rio. Historie polskich emigrantów (2017). Jej książki były tłumaczone na język hiszpański i portugalski.

Kontakt: pluta.aleksandra1@gmail.com

Marcin Raiman - mgr, Centrum Języka i Kultury Polskiej w Świecie, Instytut Filologii Romańskiej, Uniwersytet Jagielloński, Kraków, Polska.

Lektor języka portugalskiego. Zajmuje się historią i obecną sytuacją języka polskiego w Brazylii oraz polityką językową w Europie i Ameryce Południowej. Opublikował teksty: Pogranicze w twórczości Ádáma Bodora (2010), Conceptualização da actividade mental na língua portuguesa (współautor, 2011), Rumantsch grischun - ponaddialektalny jezyk retoromański w S zwajcarii (2012).

Kontakt: zold83@gmail.com

Lidia Romaniszyn-Ziomek - dr, Katedra Literatury i Kultury Polskiej, Akademia Techniczno-Humanistyczna w Bielsku-Białej, Polska.

W latach 2013-2015 pracowała w Portugalii jako lektor języka polskiego na Uniwersytecie w Lizbonie. W swoich badaniach koncentruje się na literaturze XIX i XX wieku. Jest autorką monografii Między filozofia a dramatem. 
„Maria Stuart”, „Balladyna”, „Beatryks Cenci” (2012) oraz współautorką książki „Gdzie ziemia sie kończy, a morze zaczyna”. Szkice polsko-portugalskie (2016).

Kontakt: lidiaziomek@gmail.com

Henryk Siewierski - prof. dr. hab., Departamento de Teoria Literária e Literaturas, Universidade de Brasília, Brazylia.

Historyk literatury, krytyk literacki, eseista, tłumacz. Autor m.in. książek: Spotkanie narodów (1984), Jak dostałem Brasylie w prezencie (1998), História da Literatura Polonesa (2000), Raj nie do utracenia. Amazońskie silva rerum (2006), Livro do Rio máximo do Padre João Daniel (2012), Architektura stowa i inne sækikice o Norwidzie (2012). Przełożył na język portugalski m.in. dzieła Brunona Schulza, a na polski Mensagem (Przesłanie) Fernanda Pessoi.

Kontakt: hsbrasilia@hotmail.com

Agnieszka Tambor - dr, Centrum Języka i Kultury Chińskiej, Katedra Dydaktyki Języka i Literatury Polskiej, Uniwersytet Śląski w Katowicach, Polska.

Kulturoznawczyni, jej zainteresowania związane są przede wszystkim ze współczesnym kinem polskim i możliwościami wykorzystania go w nauczaniu cudzoziemców. Te zagadnienia były także tematem jej rozprawy doktorskiej. Jest autorką książki Polska pótka filmowa. 100 filmów, które każdy cudroziemiec zobaczyć powinien oraz cyklu artykułów Półka filmowa publikowanych na łamach „Postscriptum Polonistycznego”. Opracowała również 8. tom serii $C_{z y t a j}$ po polsku, zawierający przystosowane do celów glottodydaktycznych opowiadania Zofii Nałkowskiej Pray torze kolejowym oraz Tadeusza Borowskiego Prosze państwa do gazu wraz z zestawami ćwiczeń i zadań do tych tekstów.

Kontakt: tamboragnieszka@gmail.com

Jolanta Tambor - prof. dr hab., Instytut Języka Polskiego; Szkoła Języka i Kultury Polskiej, Uniwersytet Śląski w Katowicach, Polska.

Jej zainteresowania naukowe i badawcze koncentrują się wokół następujacych zagadnień: fonetyka i fonologia współczesnego języka polskiego, język artystyczny (szczególnie prozy science fiction), sytuacja językowa na Śląsku, nauczanie języka polskiego obcokrajowców. Jest członkinią m.in. Komisji Kultury Języka Polskiego PAN, Towarzystwa Miłośników Języka Polskiego, Stowarzyszenia Polskich i Zagranicznych Nauczycieli Kultury Polskiej i Języka Polskiego jako Obcego „Bristol”. Autorka książek: Jezyyk polskiej prozy fantastyczno-naukowej (1991), Mowa Górnoślazaków oraz ich swiadomośc jezylkowa i etniczna (2006, 2008), Oberschlesien - Sprache und Identität (2011), kilkakrotnie wznawianego podręcznika Fonetyka i fonologia wspótczesnego jezyka polskiego (2000 i wyd. następne, wspólnie z D. Ostaszewska) oraz zbioru zadań do 
tegoż podręcznika Fonetyka i fonologia wspótczesnego jezyyka polskiego. Ćmiczenia (2007). Jest redaktorką wielu prac naukowych i popularnonaukowych.

Kontakt: jolanta.tambor@us.edu.pl

Małgorzata Więzik - mgr, Instytut Nauk o Literaturze Polskiej im. I. Opackiego, Uniwersytet Śląski w Katowicach, Polska.

Absolwentka filologii polskiej i kulturoznawstwa. W kręgu jej zainteresowań badawczych znajdują się m.in.: twórczość przedstawicieli szkoły ukraińskiej romantyzmu polskiego, folklor słowiański oraz podróżopisarstwo. Kontakt: malgorzata.wiezik@gmail.com

Anna Wolny - dr, Zakład Filologii Portugalskiej i Przekładoznawstwa, Uniwersytet Jagielloński, Kraków, Polska.

Ukończyła pięcioletnie studia magisterskie w zakresie filologii portugalskiej, których część spędziła w Lizbonie oraz Kurytybie. Obroniła pracę doktorską pt. Nem polonesa, nem judia. A polaca na literatura brasileira do sec. XX (Ani Polka, ani Żydówka - polaca w literaturže brazylijskiej XX wieku). Interesuje się tożsamością kobieca, teoriami feministycznymi i gender studies. Kontakt:anna.wolny@uj.edu.pl

Marcin Ziomek - dr, Katedra Studiów Środkowoeuropejskich, Akademia Techniczno-Humanistyczna w Bielsku-Białej, Polska.

Literaturoznawca i historyk idei. Zajmuje się literaturą rosyjską XX wieku, dorobkiem rosyjskiej emigracji oraz rosyjską myślą religijno-filozoficzną. Autor artykułów poświęconych życiu i twórczości Gieorgija Fiedotowa oraz Fiodora Stiepuna.

Kontakt: ziomekmarcin@gmail.com 